II Congreso Internacional Estéticas Híbridas de la Imagen en Movimiento: Identidad y Patrimonio

\title{
The Acceptance of Ephemerality and the idea of Deterioration
}

\author{
Ruth del Fresno-Guillem ${ }^{1}$ \\ ${ }^{1}$ Conservator in private practice, ruthdelfresno@gmail.com \\ https://orcid.org/0000-0002-9804-9640
}

\begin{abstract}
In an era of technology-based life, we might understand the language, but we do not pay attention to the message. The focus has been on finding strategies to preserve, document, exhibit, sell and maintain the idea of authenticity. It is essential to discuss and re-define our limits, the ethics that concern these "new" languages. This article will present some questions related to durability and acceptance. Those questions were part of a previous Ph.D. research, a study on the use of the artist's interview aimed to collect and compare the results, the mistakes, the human part of the creative process, and the conservation field. Making questions is one of the essential parts of the research, and most of the time, not an answer can be found, not even the shadow of an academically accepted answer, but some other smells were found. This article considers two cases of study of pieces made to stay for a limited period. One based on a "photography" that is not expected to last. An image made with an old technology telephone, one printed copy, on a low-quality paper, framed with an Ikea frame. No replacement is allowed, no treatments, no migration or storage of the file. The other is limited to a particular project. The interview helped to understand the idea of deterioration. An idea linked to the durability and acceptance of its death. Are we, art-related professionals, ready to accept the real ephemerality? Do we understand the preservation of the idea of deterioration? Is the collector, the institution, ready to enjoy while it lasts?
\end{abstract}

Keywords: ephemerality, deterioration, the artist's voice, acceptance, durational objects

\section{Resumen}


En una era basada en la tecnología, puede que entendamos el lenguaje, pero no prestemos atención al mensaje. Se ha centrado la atención en encontrar estrategias para preservar, documentar, exponer, vender y mantener la idea de autenticidad. Es esencial debatir y redefinir nuestros límites, la ética que concierne a estas "nuevos" lenguajes. EL presente artículo quiere exponer cuestiones relativas a durabilidad y aceptación. Estas preguntas formaron parte de la previa investigación de doctorado, un estudio sobre el uso de la entrevista al artista, que pretendía recoger y comparar los resultados, los errores, la parte humana del proceso creativo y el campo de la conservación; las preguntas fueron una parte esencial de la investigación, la mayoría de las veces no hubo una respuesta, ni siquiera la sombra de una respuesta académicamente aceptada, pero sí algunos otros olores. Este trabajo expone dos casos de estudio de dos piezas hechas para durar un tiempo limitado. Una basada en una "fotografía" que no está previsto que dure. Una imagen hecha con un teléfono de tecnología antigua, una única copia impresa, en un papel de baja calidad, enmarcada con un marco de lkea. No se permite la sustitución, los tratamientos, la migración o el almacenamiento del archivo. La otra está vinculada a un proyecto específico. La entrevista ayudó a comprender la idea de deterioro. Una idea ligada a la durabilidad y a la aceptación de su muerte. ¿Estamos preparados para aceptar lo realmente efímero? ¿Entendemos la conservación de la idea de deterioro? ¿Está el coleccionista, la institución, preparada para disfrutar mientras dure?

Palabras clave: efimeralidad, deterioro, la voz del artista, aceptación, objetos duracionales. 


\section{Introduction}

When thinking about conservators and their work, most of us have been trained in the very traditional principles of preventing and ensuring the permanence of cultural objects as works of art for the future to come. Contemporary art and, therefore, contemporary art conservation have defied any possible definition or a unique way to work. We, conservators, like to define strategies, protocols, and procedures, but it has long been proven that these rules do not apply (eternally) anymore. As Rinehart and Ippolito agreed some time ago, there is no 'one-size-fits-all' approach to preservation. It often comes down to a combination of stakeholders, including the artists themselves, to find the best strategies for each work (Rinehard, R. and Ippolito, J., 2014).

Moreover, sometimes there are no strategies at all. Glen Wharton pointed in his article "The Challenges of Conserving Contemporary Art" that among other functions, conservators' mission is to conserve the cultural significance of an object or artwork, and this most typically resides in the conceptual intention of the artist. Thus, an aim of fine arts conservation is to preserve the artists' intent. He talks about conflicts that arise when the artist's intent is contrary to the preservation doctrine (Warton, G., 2006, pp. 163-164). There are historical examples of art meant to decay or artists that assign more excellent value to a concept than its material manifestation. Many studies present the paradox of willingness to preserve what was meant to vanish (Laurenson, $P$. and van Saaze, V. 2014; Santabárbara, C. 2021; Temkin, A. 1998; Wharton, G. 2018). The present paper explores the contradictions that conservation must face when the artist decides their work is not meant to last, and it is stated in a formal interview. The article also considers the limitations established by conservation frameworks for timebased media artworks and the use of these restrictions as an intended frame of suggestions for non-durational art. It will be explored through the presentation of two cases of studies. The aim is not to establish principles and conclusions but to expose and open a discussion.

It is important to note that this article was written in a particular frame: the private practice's non-institutional experience working with emerging and middle career artists. Therefore, there are some aspects that, read from the museum perspective, might not relate. This statement means that we are not or cannot say that the ideas discussed could be applied to the museum environment. However, these concepts are presented to provoke specific reflections upon a different perception of what we are doing in the conservation field. How do we manage the information we deal with, and where is the limit, if there is one, in the migration of the expiration date? Maybe there is no change if there is no challenge.

When talking about digital-based art, the art community has gone through different stages; amazement, enjoyment, admiration, worry and, is acceptance of disappearance 
the next stage? Rubio and Wharton open the question, "How are we going to prevent the fragile memories of contemporary digital cultures from receding into oblivion?" (Rubio, F., \& Wharton, G. 2020, p. 218). With the present paper's perspective, another question is introduced: Is preservation always necessary? Are we ready, as the stakeholders of the art of our time, to accept and respect the artist's will when it goes against what we expected to be preservation?

\section{Fragility, time, and other concepts}

Impermanence and fragility have become the defining conditions of the digital age. Technologies that were ubiquitous barely a decade ago, like floppy disks, now look like archaeological relics (Rubio, F., \& Wharton, G. 2020: 218). Already in 1998, it was established that vulnerability and evanescence had determined not only the content but the form of much of the most essential (contemporary) art (Temkin, A., 1998). Nor the material, neither the technology, nor the ideas behind were stable, as we were used. Furthermore, this, of course, presents real dilemmas for collectors, curators, and conservators. It seems to be well known that as time passes, we became aware long ago about the particular fragility and challenges posed by new art forms. As users, we have been facing technological obsolescence on a daily basis. However, it is still surprising how artists perceive technology when discussing with emerging artists about the aura of eternity and permanence. While working in my Ph.D. research ${ }^{1}$, I approached the artists using technology with the question: What do you expect of your work in the future? Most artists using any digital support - either as support/tool to create the work or as the material constituent the final piece - were surprised about the question. First, they argued they did not need the services or the interaction with an art conservator as they were not making paintings, sculptures, or any of "that." After passing this barrier, they perceived the digital world as indestructible because it was on the Internet, in the cloud, in the digital world. Therefore, the perception that the artists included in the study had about time-based media art, was not accurate. After some conversations, they realized that everything pointed out in our discussions, such as obsolescence or technology fragility, were situations they had experienced but did not perceive it as deterioration or anything related to conservation; it was a matter of labels and vocabulary. The artists that did reflect about the digital "failure" had

1 Del FRESNO-GUILLEM, R. (2017). LA ENTREVISTA AL ARTISTA EMERGENTE COMO MODO DE CONSERVACIÓN PREVENTIVA Estudio aplicado a los proyectos Perspectives Art Inflammation and Me y Perspectives, Art Liver Diseases and Me [Tesis doctoral no publicada]. Universitat Politècnica de València. https://doi.org/10.4995/Thesis/10251/90410 [accessed: May 13, 2021] 
interacted openly with the idea of conservation, but they were not happy with the solutions of migration or "constantly" updating. Most of these artists perceived their work as a finished product. Once the piece was finalized, they did not want to think about it anymore. Thus, conservation was an intrusive concept, but they did understand the importance and, after becoming aware, reflected with an open mind, eager to find solutions. When deliberated on, through the artist interview and some other communications, these artists became aware of what Rubio and Warton claim: fragility is one of the key dimensions of the digital (Rubio, F., \& Wharton, G. 2020: 218). Moreover, they also talked about another fascinating factor: the paradox of time happening in digital art. When the artists were asked about time and how their work could age, most of them did not perceive time in their art. However, after some reflections, several time values were established. One value was the aesthetic perception of time - their pieces have an image, and this image will change over time. People will be able to place their artworks to a particular period in time or historical moment conferred by a particular, outmoded piece of technology (Castriota B., 2013) because of the aesthetics (it was better understood for video and photography). However, the time related to the technology was very complicated to introduce. Referencing Rubio and Wharton again, they point out that digital art are objects that do not respect the time they were made; these objects are not anchored to one point in time as it happens with traditional artworks. They belong to more than one historical moment simultaneously: they are both past and present (Rubio, F. \& Wharton, G., 2020 , p. 224). To survive, they must be "updated" in a continuum. It is here where some of the artists in the study diverged. In particular, SinQuenza, a case of study that will be discussed. The question of ageing was treated with every artist included in this research ( 82 emerging artists in total); the answers were as diverse as the group was. It shown how some artists did not perceive time as a problem because their work was not based on the material components but the idea, which was to be replicated and rematerialized at any time or moment. Time was a very abstract concept for the young emerging artist. Ageing happens in the future, and if one has not experienced it, it is a complex abstract concept. Concerning the idea of temporality, it is remarkable how Sergio Porlán ${ }^{2}$ conceived time for his work as a limited period of existence. He did not talk about ephemerality but a perception of the artwork as an event. This idea could be in line with the concept of artworks as event presented by Hanna Hölling. It is not a product-art (traditional artworks), but a process-art (artworks after the temporal turn in the sense of both the 1960s temporal shift and the temporal theories proposed) implies the concerns with that which remains (Hölling, H., 2016, p.21; Schneider, R. 2001). Hölling also talks about relative durations things instead of ephemeral or

\footnotetext{
${ }^{2}$ Interview published in Del FRESNO-GUILLEM, R. (2017).
} 
permanent artworks. So, according to her proposal, short durational works could be performance, events and long durational works like sculptures and paintings (Hölling, H., 2016, p.19). I will argue that maybe we can consider a mixed alternative, a short durational thing (the event) that produces a long durational "perceived" work, but it is instead a short durational object. In other words, an object with an expiration date.

\section{Study cases}

These cases of study are described and analyzed using ethnography-inspired methods where findings of the artwork are complemented by investigating the processes around decisions made during its creation, presentation, and conservation. As Nina Quabeck writes (Quabeck, N., 2021, p.3), is the framework of the biographical approach, in which the concept of artworks having a "biography", or a "career" allows us to trace their unfolding story as they change across time and context instead of considering artworks as static objects. Renee van de Vall et al. (2011) introduced this idea to the conservation field. The biographical approach is also well-suited to these cases of study because it acknowledges the importance of the writer. Echoing Quabeck's words:

"While within the conservation profession, a scientific mindset and a perspective perceived as objective, are still considered vitally important, researchers from outside the field such as Vivian van Saaze $(2009,2013)$ and Renee van de Vall (2015) convincingly argue that reflecting one's personal choices and dilemmas complements conservation research".

Therefore, from now on, the present paper will be written in the first person.

Several ideas will be presented through the analysis of a case of study. I am not sure if I will provide conclusions, but I will present some essential reflections result of what the artists have told me through our conversations.

These two cases might look very different, but in essence, they are not. They talk about deactivation or vanishing ${ }^{3}$; they expose the explicit vulnerability of their existence, intended from the very moment of the creative process. The artists' intent was for the pieces to expire as it was part of a specific commissioned project (Sergio Porlan) ${ }^{4}$ or because, based on the artist's words, the piece is not an artwork as for him

\footnotetext{
${ }^{3}$ Deactivation and vanishing are commonly used in contemporary art to refer to the "voluntary destruction" of a piece of art. This is not related to their natural degradation of the materials but the artist's intent.

4 Based on the artist's interview (publicly available in TestimoniArt) and further communications with the primary researcher.
} 
(SinQuenza), the artwork is the process ${ }^{5}$. The artist's intent is not a fixed perception; it has been largely studied and redefined. As Nina Quabeck points, it traditionally implies the aim to reconstruct the artist's state of mind at a specific point in time (typically at its creation or handover to an institution). Although, many scholars have talked about it as a concept in flux rather than singular and fixed (Gordon, R., 2013). Moreover, she proposes the process of intent, how it is manifested, documented, and authorized overtime (Quabeck, N., 2021, p. 2). Christian Scheidemann noted that it could not be the only parameter as artists evolve and artworks are more than the artist's production. However, in this paper, the artist's intent will be used as the artist's wish in the creative process. $^{6}$

With these two cases, I want to raise the question: what happens when the artist's expresses a wish for the artwork to expire? What should we do when the artist explicitly defines that their work must be left to vanish, not intervene, or do something? Sophie Kromholz has worked extensively on this topic, calling this as "temporary" artworks rather than ephemeral (Kromholz, S., 2016, 2018). Is the artist (always) right? (As Christian Scheidemann pointed in Glasgow 2014). Scheidemann suggests the artist is always right during the fabrication process, but maybe he/she/they is not always right after this. We know that once art is purchased, other stakeholders come to the table. Artists give up certain rights (or that is what we have learnt). We also know that not all art is meant to survive or not in its moment of inception, as happened with Strange Fruit by Zoe Leonard (Temkin, A., 1998). This idea certainly is not new. What is new is that many of these works are collected and exchanged on the open market. They are valued as a testament to an ephemeral moment or for their association with a well-known artist. (Warton, G., 2006, p. 171). Hanna Hölling talks about relative duration things instead of ephemeral or permanent artworks. Moreover, in these cases of study it can be read as expiration.

\subsection{SinQuenza, Dolores Invisibles. Is this a photography or anything else?}

The first case of study is Dolores Invisibles, a piece made by SinQuenza in 2014. (Fig. 1). This piece was one of the more than three hundred artworks of the commissioned art project Perspective -Art, Inflammation, and Me. Collection owned by an American pharmaceutical company and managed by the cathedra Arte y Enfermedades, held in

\footnotetext{
${ }^{5}$ Based on (unpublished) comments in a Telegram communication with the artist on May 11, 2021.

${ }^{6}$ I am aware that the artist's intent is a whole issue to discuss, but it will not be the focus of this paper.
} 
the Universitat Politècnica de València (UPV) in Valencia ${ }^{7}$, Spain. Both, the project, and collection were the basis for my Ph.D. research. When the artwork was catalogued in the project, it was introduced as a photography.

The perception of the piece when handled is a (two parts) photography, framed. The technical description sent by the artist said it was a picture taken with a Samsung gts5230, printed at home in a low-quality photography paper, framed with a white Ikea frame considered by the artist part of the artwork, not a protection. The only instruction was related to the order of the two images.
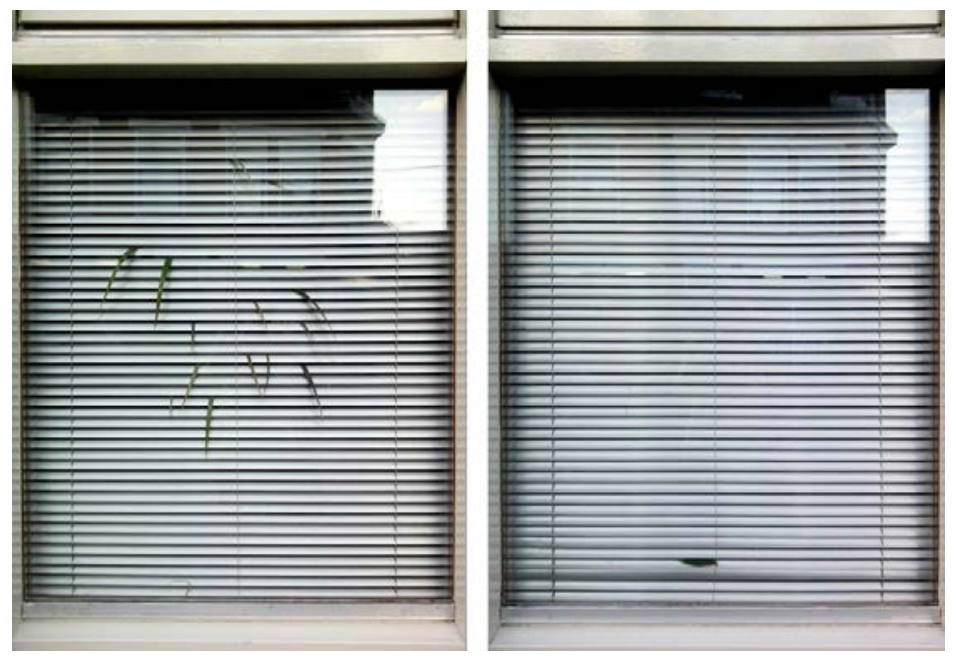

Fig. 1 Dolores Invisibles, SinQuenza. 2014. CRuth del Fresno-Guillem

An informal communication was conducted shortly after receiving the artwork, and later, a formal interview was performed ${ }^{8}$. In the interview, SinQuenza made some surprising statements. The piece was intentionally produced on low-quality materials and produced with a soon-to-be-expired technology because it was not meant to last and because the artwork is the process. The artist declared that he did not want the photography to last forever. He wanted it to vanish. He declared that he used old technology, and he did not make any copy, document, or image archive to avoid the

\footnotetext{
${ }^{7}$ Artistic project managed at the Arte y Enfermedades Cathedra, directed by Professor Pepe Miralles.

8 Published in the Anexo II of the Ph.D. Thesis (Del Fresno, R. 2017).
} 
possibility of a longer life. Based on a recent conversation, he declared: "it is more about doing something that fascinates me with the tool at hand." ${ }^{9}$ He was ok if the conservator treated the piece with respect allowing it to be preserved, but no treatment was allowed, and no change was permitted. If the artwork suffered an accident, the artwork would be either retired from the exhibition and collection or "used" as it was. It could be documented, but this documentation was only for research purposes or testimony. It was not to be a substitution of the artwork. His will was for the physical objects to not last. At the same time, after many conversations, he declared that in his creative process, the artwork was not the image the collection had but the process. For him, the artwork was a creative process (an event). Therefore, as Hölling notices when she talks about the remains, they are not, in this case, to be treated as a durational object. Is it a performance but labelled as photography? Hölling considers Zen For Film by Nam June Paik an object and an event. SinQuenza's piece could also be read similarly: object and event. To quote George Brecht words used by $\mathrm{H}$. Hölling in her presentation in Glasgow:

"George Brecht's piece The Case, 1959, are simultaneously documents, props, and leftovers. The shift between object and event is crucial. Brecht said: "Every object is an event, and every event has an object-like quality, (s)o they are pretty much interchangeable." (Hölling H. Glasgow 2014: minute 27:03).

So, according to her proposal based on David Davies work, short durational works could be performance events.

Another critical point is that SinQuenza is a persona, an alter-ego. His real name is not public. He changes from one to another, and they are not connected. They are also expected to expire. After 2015, SinQuenza's persona was deactivated ${ }^{10}$, and he became William Wolfgang Wunderbar, aka \#\#wiwowu. It lasted five years (2015-2020), and it was only digital. It created more than $25.000 \mathrm{GIFs,} \mathrm{mainly} \mathrm{on} \mathrm{Facebook} \mathrm{and} \mathrm{Instagram}$ profiles. Most of them were deleted (Fig. 2).

\footnotetext{
${ }^{9}$ Telegram communication on May 11th, 2021.

${ }^{10}$ Notice that deactivation is not killed, it entails the possibility (or not) of
} 


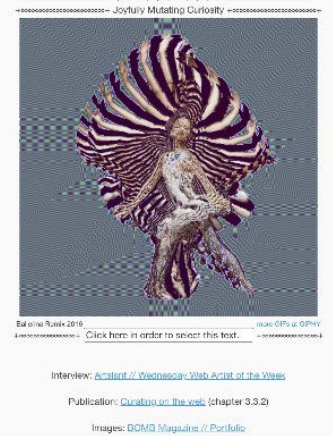

Fig. 2 WiWoWu.tumblr.com screenshot taken on May $11^{\text {th }}, 2021$.

In a recent conversation, I asked him if he killed it or let it vanish on the Internet. He said he did not kill it, he let it in the net, so it will disappear when the technology supporting it expires. It is still working, and by people's comments or interactions, it does not stop -which can be seen as a preservation strategy. The public, as in some performance theories, is the documentation and the preservation tool. For him, the alter-ego is an artwork on its own, and it lasts as long as it lasts. No media preservation is allowed.

"I'm mostly interested in the process of making, the flow of ideas and the action of transformation. So, artworks are more like a side effect" ${ }^{11}$. He decided to eliminate some of the digital creations as an act of awareness. For certain artists, there is little or no impulse to document and preserve creative work. The ephemeral nature of specific artworks requires that they will not be documented or leave no tangible trace beyond their brief existence. For some artists, the act of destruction can be a creative act. (Cianci, L. 2017 p.228). WiWoWu was not interested in destruction as an act of rebellion as some artists like the Swedish filmmaker and video artists Anders Weberg does, who has a history of destroying past work, leaving no trace other than selected images, related ephemera, the cached versions of digital items that others may have downloaded and our memories of viewing the work. He asks the question: Why must everything be accessible? SinQuenza/WiWoWu is not about destruction but not about making it last either. Furthermore, he consciously chooses digital media because of its ephemeral qualities. In his statement, when we worked together with Dolor

\footnotetext{
${ }^{11}$ Telegram communication May 11th, 2021.
} 
Invisible, he accepted the preventive conservation protocols and the respect shown. However, he did not want his work to last longer than the technology did. This approach was noticed by Marcella Lista (Chief Curator of the New Media Collection, Centre Georges Pompidou) at the talk presented in the Transformation Digital Art 2021 organized by LIMA media art platform last March 2021. Together with media conservator Alexandre Michaan, they talked about the case study on Zapping Zone: Proposals for an Imaginary Television (1990-1994). It is an artwork by Chris Marker produced by the Centre Pompidou for the exhibition Passages de I'Image in 1990. Composed of 13 video monitors, seven computer units Apple IIGS, 80 slides mounted in four lightboxes, and ten photographic prints, this major interactive installation marks the entry of digital writing forms in the art field, on the verge of the World Wide Web era. Until 2007, with the last presentation of the piece in Chris Marker's lifetime, he never ceased to modify or complete it, building an archive of 183 floppy disks, among other data carriers ${ }^{12}$.

At a particular moment of the presentation, Marcella Lista said that the artist, Chris Marker, in an informal conversation with a museum staff member, established that his piece should last what the technology lasted, no more. However, what do we do when the artist is dead, and this information is no "official"? It was not written down by the museum staff member. The impressive work done by the team involved in the conservation of digital installation is based on documentation and the prolongation of the life of the "original" elements. What should they do when these elements are no longer functional or possible to be substituted by other "original" ones? Was the artwork supposed to be a "relative durational thing"? Can this installation be considered a performance? What seems to be clear is that it will not be an easy choice. In the SinQuenza's case, the artist is alive; he stated the durability of the work and what is more, we do not know what has happened with the artwork. This piece, as I said, was part of a commissioned project. The project ended in 2016. After that, some pieces were donated to different headquarters of the pharmaceutical or patient-related associations. The responsible team for the project from the pharmaceutical changed. The whereabouts of the piece and its condition is, at this moment, unknown. What we have learnt is that the piece's existence depends on the care and longevity of the existent object. And its "preservation", or at least its testimonial existence was guaranteed by being part of the research, it is here too, therefore will not (eternally) disappear.

\footnotetext{
${ }^{12}$ Description extracted from the LIMA program. https://www.lima.nl/lima/sites/default/files/Case\%20Study\%20with\%20Pompidou.pdf [accessed May 10, 2021]
} 


\subsection{Sergio Porlán Soler, Corpe, 2013 and the idea of deactivation}

Corpe is an installation made by Sergio Porlán as part of the same commissioned art project that the previous case of study. Therefore, it was also part of the same Ph.D. research. The piece was catalogued as an installation. It consists of three wood stretchers and an object (a humidifier). The installation specifications are essential, as it is a work inspired by a person's measurement. (Fig. 3 and 4).
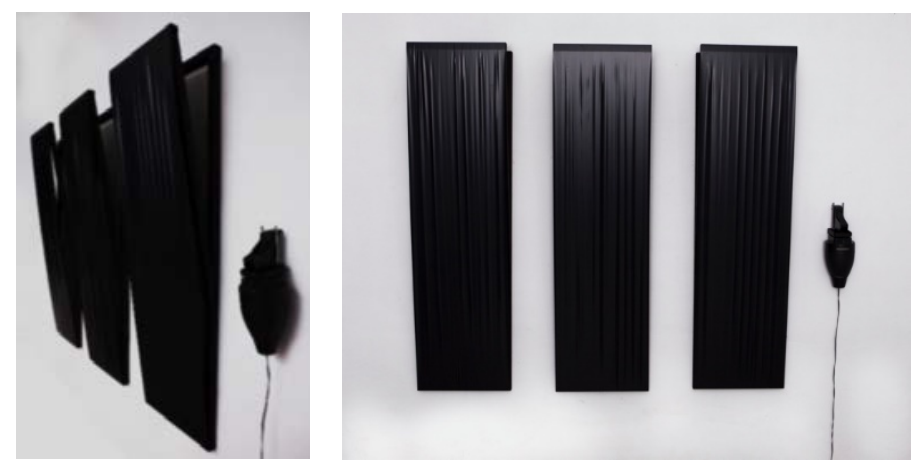

Fig. 3 y Fig. 4 Corpe, 2013. Sergio Porlán. 2021. @Ruth del Fresno-Guillem.

The three wood frames must be hung on a white wall. It must form a square representing the body with extended arms. Based on the artist's words, the materiality of the piece is only a vehicle for the concept. The piece was meant to last the time the project lasted. This installation had to be rematerialized every time it was shown. The black elastic tape had to be reapplied to the wood frames, and at the end of the exhibition, it had to be eliminated. It could be an example of what Höling points in her talk, "The acceptance of iterant materialization of works" (Hölling, H. Glasgow 2014, minute 33:25). The artist, Sergio Porlán, stated in the formal interview that his piece had an expiration date. After the project had arrived at an end, the piece was deactivated. If the owner chose to keep the objects, the artist did not recognize the objects as his work. Therefore, it was no longer a work of art but a bunch of materials.

Moreover, while the Perspective project was active, the piece had to be conserved according to the artist's instructions. His intent was clear since the creative process because the whole act was a conscious decision-making chain. How do we deal with an artwork that is going to be deactivated at a specific moment? Are the stakeholders ready to accept something with an expiration date? I would say no, we are not. As the materiality of the installation was not composed of ephemeral or short-lasting materials, it seemed more complicated to understand. This is a time-controlled piece made of lasting objects and materials. When the project ended, the owner decided to 
keep it in case the author "changed his mind" (which could be possible), but the artist disowned the authenticity of the piece. In a work of this kind, it is unnecessary to keep anything, any relic, just in case the artist changes his mind. The authenticity of the artwork is not in the constituent materials but the idea and the artist's will. Again, many concepts already presented arise. The temporality of the artwork is linked to the moment it was conceived, not to the moment it is materialized. The authenticity seems to be a matter defined by the artist himself. Does this mean that conservation is not needed? Maybe the act of standing up for the artist's wishes, the act of caring, is the conservation protocol. Ensuring the disappearance of the object at the end of the project would be the performed "treatment."

\section{Conclusions not-conclusions}

As stated at the beginning, these two cases are not that different. Both pieces can be defined as events. They could be considered remains of an act or an action. Dolor Invisible seemed to be a photography, but it is the result of creative research. It is linked to an obsolete technology with the purpose of expiration. Corpe is an art installation, but it has a performative, event-like aspect at every exhibition's rematerialization. It does not exist anymore if we follow the artist's instructions., we could argue that it does exist as an idea in the documentation or memory, but the artist stated that the piece did not exist after the project was ended. So, both pieces have expired. The conservator's role in these two cases should be to witness the dead and document it, but not to extend the life further than the stated by the artist. Although it exposes many ethical paradoxes, we must keep an open mind and re-evaluate every case and circumstance before deciding anything. Do we understand the message and the language? What the artist wished and how should we proceed and accept.

It is essential to discuss and re-define our limits, the ethics that concern these "new" languages. I will continue making questions, and I guess most of the time, not an answer will be found, not even the shadow of an academically accepted answer. Are we ready to accept the real ephemerality? Do we understand the preservation of the idea of deterioration? Letting it go as the conservation protocol. Is the collector, the institution, ready to enjoy while it lasts?

Maybe, Leonard Coehn was right, and we should remember his anthem:

There is a crack, a crack in everything

That's how the light gets in (Anthem, by Leonard Cohen, 1992 album The Future) 
The Acceptance of Ephemerality and the idea of Deterioration

\section{References}

CASTRIOTA, B. (2013). Equipment Significance and Obsolescence in Diana Thrater's The Bad Infinite. A Case Study in the Cult of Unintentional Monuments. [poster]. HS. Conservation: Cultures and Connections. Edited by Brajer, I. ICOM-CC Theory and History Working Group. https://doi.org/10.4000/ceroart.3665 [accessed: July 13th, 2021].

CIANCI, L. (2017). Small acts of resistance: teaching young and emerging artists sustainable preservation strategies for contemporary creative practice, Archives and Manuscripts. 45 (3), 216-236, DOI: 10.1080/01576895.2017.1376286 [accessed: May 5, 2021].

Del FRESNO-GUILLEM, R. (2017). La Entrevista Al Artista Emergente Como Modo De Conservación Preventiva Estudio aplicado a los proyectos Perspectives Art Inflammation and Me y Perspectives, Art Liver Diseases and Me [Tesis doctoral no publicada]. Universitat Politècnica de València. https://doi.org/10.4995/Thesis/10251/90410 [accessed: May 13/ 2021]

GORDON, R., and HERMES, E. (2013). The Artist's Intent in Flux. CeROART [Online], HS|2013. Conservation: Cultures and Connections. http://doi.org/10.4000/ceroart.3527 [accessed: May 13, 2021]

HÖLLING, H. (2014) (Keynote 2) The Aesthetics of Change: On the Relative Durations of the Impermanent. in Authenticity in Transition Conference 1-2 December 2014 at The Glasgow School of Art. https://vimeo.com/167091779?ref=em-share [accessed: May 11/2021]

HÖLLING, H. (2016). The Aesthetics of Change: On the Relative Durations of the Impermanent. In Authenticity in Transition, edited by Erma Hermens and Frances Robertson, 13-24. London: Archetype Publications.

KROMHOLZ, S. (2016). Teh Artwork is not Present: An Investigation into the Durational Engagement with Temporary Artworks. PhD thesis, University of Glasgow.

KROMHOLZ, S. (2018). Absence makes the heart grow fonder: rethinking intentional material loss in temporary art. In Studies in Theater and Performance. 38:3, 224-237. https://doi.org/10.1080/14682761.2018.1507203 [accessed: May 13, 2021]

LAURENSON, P. and van SAAZE, V. (2014). Collecting Performance-Based Art: New Challenges and Shifting Perspectives. In Performativity in the Gallery: Staging Interactive Encounters, ed. Outi Remes. Bern: Peter Lang, 27-41.

QUABECK, N. (2021). Reframing the Notion of "The Artist's Intent:" A Study of Caring for Thomas Hirschhorn's Intensif-Station (2010). Journal of the American Institute for Conservation, 1-15. DOI : 10.1080/01971360.2020.1826151

RINEHART, R. and IPPOLITO, J. (2014) Re-collection: Art, New Media and Social Memory, The MIT Press, Cambridge, MA and London. 
Ruth Del Fresno-Guillem

RUBIO, F., \& WHARTON, G. (2020). The Work of Art in the Age of Digital Fragility. PUBLIC CULTURE, 32(1), 215-245. https://escholarship.org/uc/item/4vs431tv\#main [accessed: May 11, 2021] http://dx.doi.org/10.1215/08992363-7816365 Retrieved from https://escholarship.org/uc/item/4vs431tv

SANTABÁRBARA MORERA, C. (2021) El tiempo como materia artística en la conservación del arte contemporáneo. Boletín Museo e Instituto Camón Aznar, 117 (pp 55-68).

SCHEIDEMANN, C. (2016). Why Not Ask the Artist? VoCA Journal 2016. http://journal.voca.network/why-not- ask-the-artist/. [accessed: May 11, 2021]

SCHNEIDER, R. (2001). Performance Remains, Performance Research. A Journal of the Performing Arts, $6: 2,100-108$, DOI : 10.1080/13528165.2001.10871792 [accessed : May 13, 2021]

TEMKIN, A. (1998) Strange Fruit. In Mortality Immortality? The Legacy of 20th-Century Art. https://www.getty.edu/conservation/publications_resources/newsletters/13_2/news1_1.ht $\mathrm{ml}$ [accessed: May 13, 2021]

VALL, R., HÖLLING, H., SCHOLTE, T., AND STIGTER, S. (2011) Reflections on a Biographical Approach to Contemporary Art Conservation. In ICOM-CC 16th Triennal Meeting preprints, Lisbon, 19-23 September. Edited by BRIDGLAND, J. Almanda: Criterio. https://www.researchgate.net/publication/299510801_Reflections_on_a_biographical_appr oach_to_contemporary_art_conservation [accessed: May 7, 2021]

WHARTON, G. (2006) The Challenges of Conserving Contemporary Art. In Altshuler, Bruce (ed.) Collecting the New: Museums and Contemporary Art. Princeton: Princeton University Press. 164-178. http://glennwharton.net/wp-content/uploads/2015/07/WhartonChallenges-Conserving-Contemporary-Art.pdf [accessed: May 9, 2021]

WHARTON, G. (2018) Bespoke ethics and moral casuistry in the conservation of contemporary art, Journal of the Institute of Conservation, 41:1, 58-70, DOI: 10.1080/19455224.2017.1417141 [accessed: May 10, 2021]

WIWOWU, ttps://wiwowu.tumblr.com/ source for the art project net-based for the alter-ego William Wolfgang Wunderbar [accessed: May 11, 2021] 